\title{
Establishment of Population-Based Stroke Registry in Ludhiana City, Northwest India: Feasibility and Methodology
}

\author{
Jeyaraj Durai Pandian ${ }^{a}$ Gagandeep Singh ${ }^{b}$ Rajinder Bansal ${ }^{b}$ Birinder S. Paul ${ }^{b}$ \\ Monika Singla ${ }^{b}$ Shavinder Singh ${ }^{c}$ Shweta J. Verma ${ }^{a}$ Premjeeth Moodbidri ${ }^{a}$

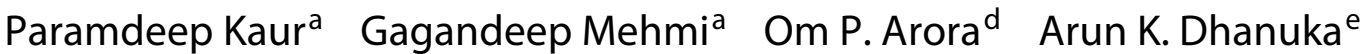 \\ Meenakshi Sharma ${ }^{f}$ Collaborators and the Indian Council of Medical Research \\ Task Force Group \\ a Department of Neurology, Stroke Unit, Christian Medical College and Hospital, ${ }^{\mathrm{b}}$ Department of Neurology, Dayanand \\ Medical College and Hospital, ' Department of Community Medicine, Christian Medical College and Hospital, ${ }^{\mathrm{d}}$ Arora \\ Neuro Centre, and ${ }^{e}$ Deep Hospital, Ludhiana, and ${ }^{\mathrm{f}}$ Non Communicable Diseases Division, Indian Council of Medical \\ Research, New Delhi, India
}

\section{Key Words}

Developing countries · Feasibility · India · Methodology ·

Population-based studies · Stroke

\begin{abstract}
Background/Aims: The Indian Council of Medical Research (ICMR) initiated the Task Force Project to evaluate the feasibility of conducting a population-based stroke registry in Ludhiana city, Punjab, Northwest India. Methods: All firstever, stroke patients over 18 years from the city of Ludhiana were included in the study from March 26th 2010 to March 25th 2011. Stroke information was collected based on the WHO STEPS approach from the participating hospitals, scan centres and doctors. Modified Rankin Scale (mRS) was administered by telephonic interview at 28 days after stroke. The information on stroke deaths was obtained from the Municipal Corporation (MC) office. Results: A total of 905 firstever stroke patients were documented. After excluding duplicate cases and patients from outside the city, 493 patients were included. The practical issues identified in data collec-
\end{abstract}

tion from these centres were reluctance to take informed consent, lack of willingness to share the data, difficulty to identify key persons from each centre, retrieving medical records from public hospitals and poor documentation of deaths in MC office. Conclusion: Population-based stroke registry was feasible in an urban population with the above methodology. The issues related to feasibility were identified and necessary changes were made for the main phase of the registry.

(c) 2015 S. Karger AG, Basel

\section{Introduction}

Stroke is a leading cause of death and disability across the world. It is projected that there will be 7.8 million stroke-related deaths by the year 2030 and most of these deaths will occur in low-income and middle-income countries (LMICs) including India [1].

Over the past decade, although the annual incidence rates of stroke have shown a decline from 221.19/100,000

\section{KARGER 125}

(c) 2015 S. Karger AG, Base

0251-5350/15/0442-0069\$39.50/0

E-Mail karger@karger.com

www.karger.com/ned
Dr. Jeyaraj D. Pandian, MD, DM, FRACP

Department of Neurology, Head of Research

Betty Cowan Research and Innovation Center

Christian Medical College and Hospital, Ludhiana, Punjab 141008 (India)

E-Mail jeyarajpandian@hotmail.com 
(2005) to $217.26 / 100,000$ (2010) in high-income countries, the incidence rates have marginally increased in the LMICs from $277.48 / 100,000$ (2005) to $281.12 / 100,000$ (2010) [2]. In 1990-2010, the incidence of stroke increased significantly in adults aged 20-64 years in LMICs [2].

Reliable information on the incidence of stroke in LMICs is scarce. Available studies on incidence lack uniform methodology [3-10]. Recent studies reported from India on stroke incidence also have methodological issues. A survey done in Kolkata, in eastern India, was a 2-year community-based, door-to-door study. CT scan/ MRI reports were available only for a small proportion of stroke patients $[11,12]$.

The Trivandrum registry from South India was carried out for 6 months and information was obtained on selected risk factors. The region is distinctive in being highly literate and hence findings from this registry cannot be extrapolated to the rest of India [13].

There is lack of reliable and comparable data on stroke incidence, causes, trends and outcomes across the nation $[14,15]$. India is a vast country with diverse sociocultural and economic settings. The incidence studies undertaken so far have been in selected metropolitan cities. Hence, the Indian Council of Medical Research (ICMR) created a Task Force in the year 2008 to explore the possibility of creating a stroke surveillance system in the country. It was decided by this Task Force Group to establish the feasibility of carrying out a population-based stroke registry in Ludhiana city in north India and in the rural region of Bangalore in south India. The purpose of this study was to establish a model for stroke surveillance, which can be expanded to other regions of the country.

The project was divided into 2 phases. Phase I comprised a feasibility study and phase II included the execution of the comprehensive epidemiological study. In this article, we describe the phase I of the project.

\section{Objective of Phase I}

To determine the feasibility of capturing incident cases of stroke from private and public health care facilities and private imaging centres across the urban regions of Ludhiana city in Northwest India.

\section{Material and Methods}

\section{Study Population and Area}

The registry covers the geographical limits of Ludhiana city (Punjab) with an area of $159.37 \mathrm{~km}^{2}$ situated in the northwestern part of India. The city is situated between the latitude $30^{\circ} 51^{\prime} 10^{\prime} \mathrm{N}$ and $30^{\circ} 57^{\prime} 20^{\prime} \mathrm{N}$ and longitude $75^{\circ} 46^{\prime} 00^{\prime} \mathrm{E}$ and $75^{\circ} 56^{\prime} 20^{\prime} \mathrm{E}$. Based on certain criteria, the Municipal Corporation (MC) has divided the population into 75 wards (fig. 1). According to the 2001 census, the population of the city was $1,398,467$ (men: 793,142 ; women: 605,325) out of which 935,925 (men: 531,874; women: 404,051) people were over 18 years. This phase 1 study was conducted from March 26th 2010 to March 25th 2011. The first 5 months was the preparatory phase, followed by 7 months of the feasibility phase (data collection).

\section{Inclusion Criteria}

(a) first-ever stroke

(b) age $\geq 18$ years

(c) resident of the Ludhiana city for more than 6 months

\section{Preparatory Phase}

The health system in India is divided into two, namely, government health system run by the respective States and the private health system managed by the private groups. In government hospitals, the treatment is subsidized, whereas in private hospitals, patients and their relatives have to bear the entire cost of treatment. In addition, there are alternative systems of medicine like Ayurveda, Homeopathy, Siddha and Unani.

\section{Selection of Study Sites}

The Indian Medical Association, the Physicians Forum and General Practitioners Association of Ludhiana were approached to obtain hospital and imaging inventory of Ludhiana city. The organizations that are involved in stroke management and the central administrative units for collecting births and deaths were listed. The list included all tertiary care teaching hospitals, private nursing homes, private neurology centres, private scan centres and general practitioners (GPs).

A total of 387 health care facilities including GPs were identified. Details of decision-making authorities at these centres along with their contact addresses were obtained. An official letter to these centres was sent, informing and requesting their participation and cooperation. The medical records department was requested to keep the records of all stroke patients separately on a daily basis. The research staff approached these centres for the initial survey. They obtained data on those stroke patients seeking medical help, using the patient load questionnaire (online suppl. file 1; for all online suppl. material, see www.karger.com/doi/ $10.1159 / 000371520)$. This questionnaire included information about the number of stroke patients seen in a week or admitted in the hospital in a week.

Based on the patient load, the centres were classified as

(a) high priority ( $>7$ cases/week)

(b) medium priority (3-7 cases/week)

(c) low-priority centres ( $<3$ cases/week)

Visits to high-priority centres were carried out on a daily basis, to medium-priority centres on a bi weekly basis and to low-priority centres once a week.

Based on the patient load information collected from health centres in phase I, 34 potential centres ( 9 private scan centres, 15 private hospitals, 2 public hospitals, 8 physiotherapy centres) and 125 GPs were identified. There are approximately 170 beds to manage stroke patients in these centres.

Out of 125 GPs, only 14 saw more than 3 stroke patients per week. GPs sent all the stroke patients for obtaining imaging to
Pandian et al. 


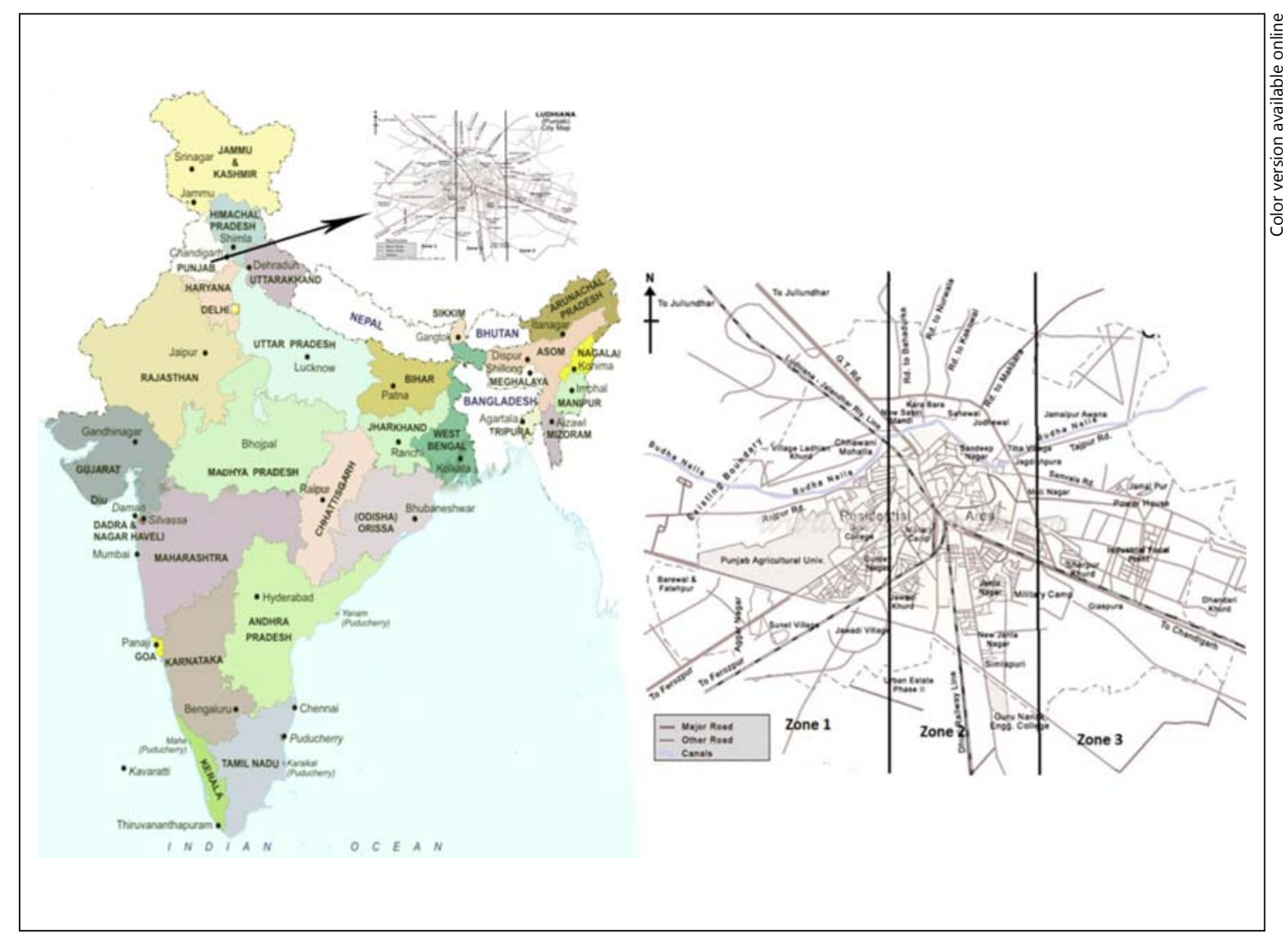

Fig. 1. Ludhiana City Map.

scan centres. It was practically impossible to meet all the GPs. Out of 14 GPs, 6 participated in the study. The alternative medicine practitioners had difficulty in filling the forms and the practice trend was that all of them referred stroke patients to the scan centres. The patients returned and showed the scan reports to them.

Except two private hospitals, all other identified centres participated in the study. These 2 private hospitals did not participate due to administrative reasons. This was discussed in detail in ICMR Task Force meeting. It was decided to collect basic information like the number of stroke patients seen/admitted, type of stroke, and the place of residence from the stroke patients.

After a stroke, most of the patients contacted family doctors and GPs. In Ludhiana city, 38\% of the stroke patients reached hospital directly, while $59 \%$ consulted private doctors before reaching a hospital [16]. This was the pattern of health- seeking behavior of stroke patients in the city.

Participating centres were offered an incentive of INR 50 (USD 0.85 ) for each completed form. However, only a few hospitals and scan centres opted to receive the incentive.

\section{Mortality Data}

The registration of death in India is not well developed and only about $67 \%$ of the deaths are recorded [17]. In Ludhiana city, there are a total of $10 \mathrm{MC}$ centres, which collect death information: 2 main centres and 8 sub centres. In the initial phase of data col- lection, data was collected only from the main centres. It took 3-4 months to receive permission from the administrative office to collect death data from MC office.

In the MC office, two types of death records were maintained: hospital deaths and house deaths. Hospital death certificates were screened once a month. From the hospital death certificates, research staff identified those deaths due to stroke. Twenty percent of the home deaths recorded by the MC office were subjected to verbal autopsy using door-to-door survey.

\section{We Used the Following Definitions}

Stroke

WHO's definition of stroke: 'a focal (or at times global) neurological impairment of sudden onset, and lasting $>24 \mathrm{~h}$ (or leading to death), and of presumed vascular origin' with or without confirmation of imaging [18].

First-ever (also called 'first in a lifetime'): it refers to people who have never had a stroke before and who have had first stroke during the study period.

\section{Risk Factors}

Risk factors (diabetes mellitus, hypertension, hyperlipidemia, atrial fibrillation, carotid stenosis, previous history of transient ischemic attack (TIA), rheumatic heart disease, coronary artery disease, tobacco current and past use) are defined in online supplementary file 2 [19-24]. 
The Following Questionnaires Were Used for Data Collection (online suppl. file 3)

Questionnaire 1: For Hospitals and Outpatient Department

(OPD) Patients

This questionnaire included information about the demographic details, type of stroke, diagnosis modality, symptoms, risk factors and outcome using modified Rankin Scale (mRS) at the time of discharge.

Questionnaire 2: Patients from Scan Centers

This questionnaire is similar to questionnaire 1 with information on age, gender, type of stroke, diagnosis modality and risk factors.

Questionnaire 3: Deaths Registered with MC Centres

This questionnaire gave information on age, gender, date and cause of death.

Questionnaire 4: Verbal Autopsy Form

Information about age, gender, date of verbal autopsy, date and cause of death were collected in this form.

\section{Workshop and Training}

The principal investigator (PI) and research staff visited the collaborating centers. They discussed the importance of the study and the methods of data collection. In order to encourage participation in the registry, a continuing medical education (CME) program was conducted for the physicians in August 2010. About 55 physicians attended the CME. The PI gave a presentation about the registry and also discussed the questionnaires in detail. The entire research team was introduced to the physicians. A separate workshop and training was organized at the host institution in the same month. Representatives from ICMR were present during the workshop. This program covered the theoretical aspects as well as the practical information on filling the forms. During the workshop, a manual of operations comprising questionnaires and definition of terms was given to all the participating centers. We also organized another meeting for the alternative medicine practitioners of the city. All the field workers were trained in $\mathrm{mRS}$ and were certified.

\section{Data Collection Phase}

For the convenience of the research staff and also based on the distribution of hospitals and scan centres, the city was divided into 3 zones (fig. 1). The research staff approached selected centres and obtained data on the first-ever stroke patients using the questionnaires.

\section{Hospitals}

Research teams visited selected hospitals (public, private and physiotherapy centres) at least thrice a week. They met the nominated person, reviewed available records and transferred information to the form. They used questionnaire 1 for data collection (online suppl. file 3).

\section{GPs}

Attempts were made to identify 'mild and transient cases of stroke from few general practitioners/family physicians. We encouraged the GPs to document information in a register along with verification by a field staff at weekly intervals. Questionnaire 1 was used to collect information from GPs (online suppl. file 3).

\section{Scan Centres}

The research team visited the selected scan centres at least thrice a week and screened the reports of CT scans/MRI scans for stroke. New acute lesions corresponding to the symptoms of the patients were taken as the criteria to define stroke from scan centres.

They used questionnaire 3 for data collection (online suppl. file $3)$. One person in the scan centre collected this information.

\section{Classification of the Type of Stroke}

In the hospital, stroke classification was done by a neurologist or a physician based on the scan findings. In scan centres, stroke classification was confirmed by a radiologist. All these investigators underwent formal training before the start of this study. The centres were checked randomly regarding accuracy of data collection.

Outcome Using mRS

For hospitalized patients, outcome was assessed at the time of discharge using mRS. At 28 days post stroke, telephonic follow up was performed for all the recruited patients (from hospitals, GPs and scan centres). The research staff administered the $\mathrm{mRS}$ and collected the data using questionnaire 2 (online suppl. file 3).

\section{Mortality Data from MC Office}

Questionnaire 4 was used to document the details of stroke deaths from the hospital death certificates and questionnaire 5 was completed for stroke deaths identified during verbal autopsy (online suppl. file 3). Verbal autopsy was done by research staff using the door-to-door method. They collected the information regarding home deaths from the MC and based on the addresses given in the home death certificates, they went to the house and interviewed the relatives.

\section{Data Storage and Privacy}

In the initial task force, meeting the consent process and practical issues in obtaining consent from different health care facilities were discussed. It was decided to collect data without obtaining consent. The data was de-identified and password protected in PI's research office computer. But in the subsequent meetings, when the preliminary observations were discussed, it was decided to obtain consent from all the participating centres. Research staff and nodal contact staff obtained consent from hospitals, GPs and scan centres. At the time of VA, research staff took the consent. The barriers were overcome by making regular visits, having meetings and individual discussions with participating centres. So only during the first three months, we didn't take the consent.

\section{Quality Assurance}

All the forms were individually seen by PI. The PI visited the participating centres twice a month to monitor data collection and identify practical issues.

This project was approved by institutional ethics committees of Christian Medical College \& Hospital, Dayanand Medical College \& Hospital, Ludhiana and permission was obtained from all the other centres.

Descriptive statistical measures were computed using SPSS version 21.0 (Armonk, N.Y., USA: IBM Corp 2013). 
Table 1. Identification and patterns of duplications

Identification of duplicate case

At least 3 variables matched: age, gender, contact number and address

\begin{tabular}{ll}
\hline Patterns of duplicate cases & Data included from \\
\hline Data collected from same centre more than once & Only one form with complete data was included \\
Scan centre and hospital of the same site & Hospital form* \\
Scan centre, $\mathrm{GP}^{\dagger}$ and Hospital & Hospital form \\
$\mathrm{MC}^{\ddagger}$ and hospital data & Hospital form
\end{tabular}

${ }^{*}$ Form has detailed information; ${ }^{\dagger}$ general practitioners; ${ }^{\ddagger}$ Municipal Corporation.

\section{Results}

Data was collected from 16th August 2010 to 25th March 2011. The initial data and questionnaires were reviewed by the ICMR task force members in a separate meeting. On the recommendations of ICMR task force members, minor changes were made in the questionnaires (demography, type of stroke, symptoms in questionnaire 1 and verbal autopsy form) and the centers were asked to maintain a separate register in the emergency department to avoid under-recording of data, and also track the duplication of cases within the hospitals.

\section{Duplicate Cases}

Actions were taken to check the duplication of cases from hospital and scan centres, hospital and MC data. The criteria to identify duplicate cases were to match at least 3 variables out of age, gender, address and contact number. The patterns of duplication of cases are given in table 1.

\section{Feasibility Issues Identified}

There were a number of feasibility issues identified during the data collection from public hospitals, private hospitals, GPs and scan centres (table 2).

\section{Data Collection Phase}

A total of 905 first-ever stroke patients were enrolled from all the centres. Out of 905 patients, it was found that 97 cases were duplicated. After excluding these duplicate cases, TIA and patients from outside the Ludhiana city, 493 patients were included in the analysis (fig. 2). Out of 493 patients, 341 were from private hospitals, 73 from scan centers, 63 from public hospitals, 10 from death re- cords of MC centres ( 3 hospital deaths record at MC and 7 by VA), 2 from physiotherapy centers and 4 from GPs (table 3).

Two private hospitals didn't participate in the study. Over a period of 4 months basic data was collected from these centers. Eighty nine patients were seen during this time in these two hospitals. Out of 89 patients, 76 were from outside the city and 2 patients had recurrent stroke, leaving only 11 first-ever stroke patients whose data was obtained from these two hospitals in 4 months' time.

\section{Demographic Details}

The mean age of patients was $58 \pm 15$ years and there were 308 (62.5\%) men. Majority were Sikhs - 199 (49\%) (table 4).

\section{Discussion}

Unlike many incidence studies done in India and other LMICs, this task force project had exclusively studied the problems in carrying out population-based stroke registry.

We identified important issues in carrying out the project. The foremost problem was the initial reluctance in sharing patient data by hospitals, scan centres and GPs with the research team. However, with repeated visits and reassurances, the centres started cooperating. Reluctance in obtaining informed consent by the participating centres was another major issue in the initial phase of the project. However, when the research team gave the assurance that patients data would not be shared, the participating centres agreed to obtain the informed consent. The poor quality of data from public 
Table 2. Feasibility issues identified in data collection phase

\begin{tabular}{|c|c|c|}
\hline Participating centres & Feasibility issues & Solution \\
\hline \multirow[t]{3}{*}{$\begin{array}{l}\text { Public/private hospitals, } \\
\text { GP's }{ }^{\dagger} \text { and scan centres }\end{array}$} & Reluctance to take informed consent & $\begin{array}{l}\text { Assurance was given to participating centres that } \\
\text { patient's data would not be shared or used for any } \\
\text { other purpose }\end{array}$ \\
\hline & Difficulty to identify key person & $\begin{array}{l}\text { A key person was identified in all centres. After } \\
\text { repeated requests and meetings }\end{array}$ \\
\hline & $\begin{array}{l}\text { Incomplete follow up at } 28 \text { days: frequent change } \\
\text { of mobile phone numbers of patients }\end{array}$ & Collected two or more mobile phone numbers \\
\hline Public hospitals & $\begin{array}{l}\text { Difficult to retrieve information from the medical } \\
\text { records }\end{array}$ & $\begin{array}{l}\text { Identified two nurses who then collected } \\
\text { information from the patients }\end{array}$ \\
\hline $\mathrm{GPs}^{\dagger}$ & $\begin{array}{l}\text { Difficulty in capturing minor strokes: } \\
\text { (i) Did not share their data } \\
\text { (ii) Unable to complete the form }\end{array}$ & $\begin{array}{l}\text { GP's referred all the patients to scan centres. } \\
\text { All the scan centres participated in the project }\end{array}$ \\
\hline Private hospitals & $\begin{array}{l}\text { Reluctance to share the data ( } 2 \text { hospitals declined } \\
\text { to share their data) }\end{array}$ & $\begin{array}{l}\text { With repeated visits and assurances, the centres } \\
\text { cooperated with the research staff }\end{array}$ \\
\hline Scan centres & Data was deleted daily in few scan centres & The research staff visited these centres daily \\
\hline \multirow[t]{2}{*}{ Mortality data from $\mathrm{MC}^{\ddagger}$} & Verbal autopsy: incomplete addresses & $\begin{array}{l}\text { A questionnaire was designed for home deaths, } \\
\text { which was completed by the MC staff or the } \\
\text { relative when they came to report home death }\end{array}$ \\
\hline & $\begin{array}{l}\text { Hospitals deaths records: poor documentation of } \\
\text { details of deaths }\end{array}$ & - \\
\hline
\end{tabular}

Fig. 2. Shows recruitment algorithm.

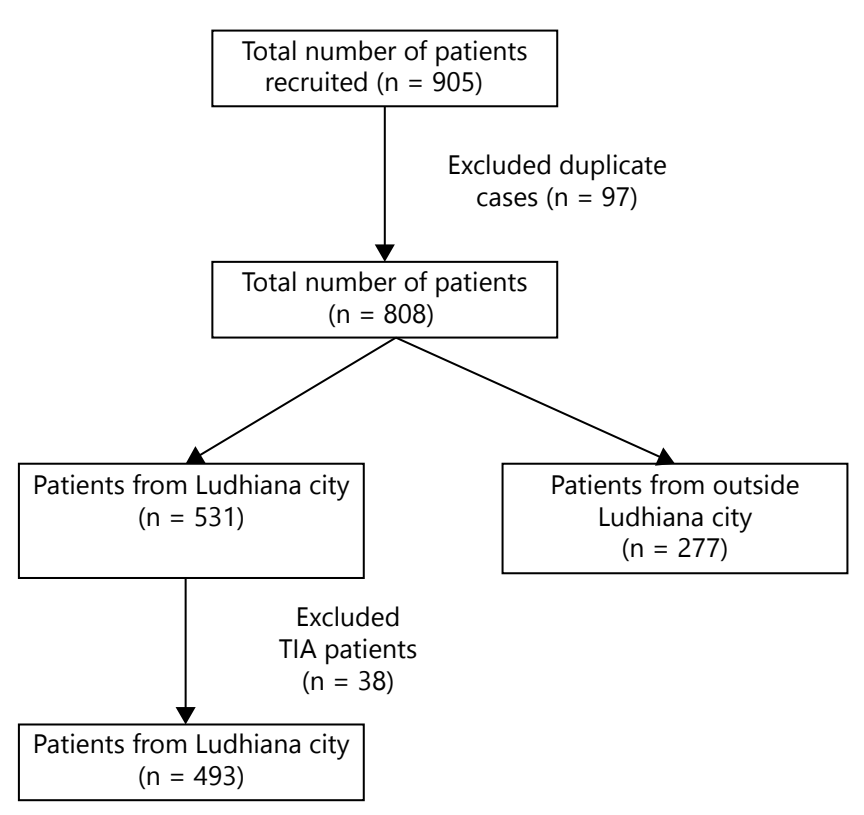


Table 3. Distribution of patients recruited from various participating centres $(n=493)$

\begin{tabular}{lcl}
\hline Source & Patients & Percentage \\
\hline Public hospitals & 63 & 13 \\
Private hospitals & 341 & 69 \\
Scan centers & 73 & 15 \\
General practitioners & 4 & 0.7 \\
Physiotherapy centers & 2 & 0.4 \\
Municipal corporation data & & \\
$\quad$ (hospital death records) & 3 & 0.6 \\
Verbal autopsy & 7 & 1.4 \\
\hline
\end{tabular}

Table 4. Demographic details of stroke patients

\begin{tabular}{lll}
\hline Variables & $\begin{array}{l}\text { Patients } \\
(\mathrm{n}=493)\end{array}$ & Percentage \\
\hline Age, years (mean $\pm \mathrm{SD})^{\S}$ & $58 \pm 15$ & \\
Gender & & \\
$\quad$ Men & 308 & 62.5 \\
$\quad$ Women & 185 & 37.5 \\
Religion & & \\
$\quad$ Hindu & 187 & 46 \\
$\quad$ Sikh & 199 & 49 \\
$\quad$ Others* & 21 & 5 \\
Education & & \\
$\quad$ Lower & \\
$\quad$ Upper & 116 & 32 \\
Occupation & 245 & 68 \\
$\quad$ Employed & & \\
$\quad$ Unemployed & 191 & 49 \\
\hline
\end{tabular}

$\S$ Standard deviation; * Muslim, Jain, Christian; ${ }^{\ddagger}$ less than primary school completed.

hospitals records was another hindrance faced by the registry and was tackled by identifying and training two nurses from these hospitals who then collected data from the patients.

India is a market leader in the use of mobile phones. Mobile phones are cheap and are available even with the people of lower socioeconomic status. However, it is common practice in India that people have more than one phone number. In the initial phase of the study, the telephonic follow-up rate was not satisfactory due to frequent change in mobile phone numbers. The problem was resolved through the collection of information on two or more mobile phone numbers.

Feasibility of Population Based Stroke Registry
GPs are usually qualified in allopathic medicine or a qualified physician or a surgeon. They run private clinics where patients come for consultation. They see more than 100 patients every day on an average. They don't have any computerized or paper record system and the patients are given prescription or investigation forms to carry out tests in private laboratories and scan centres. There is no restriction on the number of GPs in any region. When the patients come for a revisit, previous prescription forms are brought along. It was difficult for GPs to complete the data form and maintain a register for stroke patients in the midst of their busy clinical practice. GPs sent all the stroke patients for obtaining imaging to scan centres. It was practically not possible to meet all the GPs by the research staff.

As per the WHO STEPS Stroke Project manual, nonfatal, non-hospitalized events are the most challenging proportion of the stroke patients to identify. Continuous surveillance of communities for nonfatal cerebrovascular events managed out of hospital is impractical. In areas where the locals often use GPs, efforts should be directed to include them in the surveillance activities [18].

The records of stroke-related deaths by MC were incomplete. The incompleteness of vital registration system in India as compared to high-income countries is a major challenge in data collection for stroke-related mortalities occurring at home. To improve the documentation of home deaths, we designed a questionnaire that was completed by the MC staff or the relative when they came to report the home death (online suppl. file 4). Based on the information provided in the questionnaire, the research staff carried out telephonic verbal autopsy in a small proportion of people who died at home. There were very few stroke deaths identified in the feasibility phase. The reason for this was delay in obtaining permission from administrative office to collect death data from MC centres (3-4 months). Moreover, it takes approximately 2 months for the hospital authority to send the death certificates of in-hospital deaths to MC. In the feasibility phase, data was collected from only two main centres. In the main phase of the study, we collected information from all the centres.

Regular educational programs were held for the participating centres that improved their cooperation in the study. Advertisements were placed in leading local newspapers in order to capture patients who received treatment from outside the Ludhiana city. This method helped in identifying a few stroke patients.

Ludhiana is a small city, which has good health care facilities as compared to the other metropolitan cities in

Neuroepidemiology 2015;44:69-77 DOI: $10.1159 / 000371520$ 
India. All major hospitals and scan centres participated in the study; thus, the chances of missing information about a nonfatal stroke is very low. A door-to-door survey was done at the end of the third year (main phase) in a population of 19,051 to explore the completeness of case ascertainment. The incidence rates were similar in both doorto-door survey and the present study using the WHO STEPS approach. The incidence rate in door-to-door survey was $142 / 100,000$ as compared to the data obtained by the WHO STEPS methodology which was $140 / 100,000$ (3rd year data; unpublished).

The advantages of this data collection method are that it allows an increase in sampling frame with a low-cost budget in comparison to a door-to-door survey covering the same population. Limitations: Minor strokes will be missed as they might not report to facility and people might seek treatment from medical facilities outside the capture zone or from quacks (a major issue in the given setting). However, based on our experience, a majority of the stroke patients seen by GPs were sent for obtaining $\mathrm{CT} / \mathrm{MRI}$ scans. All the scan centres in the city participated; hence the chances of missing stroke patients managed as outpatients are less.

Two private hospitals didn't participate in the study. Over a period of 4 months only 11 first ever stroke patients were seen in these 2 hospitals. Hence, the proportion of patients not recruited from these two hospitals is small.

This paper highlights the methodological problems in carrying out a population-based stroke registry in an urban population of a developing country like India. Based on the local solutions for the problems, we were able to carry out the phase 2 of the study for 2 years successfully. Any surveillance project on stroke in LMICs will take time and the methods need to be adapted according to local requirements.

\section{Acknowledgement}

We thank Mrs. Madhu Bala for data entry.

\section{Collaborators}

Dr. Manoj K. Sobti: Sobti Neuro and Super Specialty Hospital. Dr. Harish Sehgal: Guru Teg Bahadur Charitable Hospital.

Dr. Mohanjeet Kaur: Shree Raghunath Hospital.

Dr. Tushar Arora, Dr. T.N. Shadangi: Deepak Hospital.

Dr. Ashish Saxena: Mediciti Hospital.

Dr. Jeetamol S. Gill, Ramandeep S.Brar: Delta Heart Centre.

Dr. Anakhvir S. Gill: Heart Beat Diagnostics Centre.

Dr. Sandeep S. Bakshi: Ace Health Ways.

Dr. Sandeep S. Pawar: Kuka Diagnostic Centre.

Dr. Sarvpreet S. Grewal, Dr. Sukhdeep S. Jhawar: Department of Neurosurgery, Christian Medical College, Ludhiana.

Sh. Pradeep K. Litoria: Geology, Water Resources and Geoinformatics Division, Punjab Remote Sensing Centre, Ludhiana.

\section{Funding}

The population-based stroke registry was supported by Indian Council of Medical Research, New Delhi (grant ICMR/SWG/ 22Neuro/2008-NCD-1(2009-0956) A\&B).

\section{Disclosure Statement}

None declared.

\section{ICMR Task Force Group}

Dr. Bela Shah: Non Communicable Diseases Division, Indian Council of Medical Research, New Delhi.

Dr. D.K. Shukla: Non Communicable Diseases Division, Indian Council of Medical Research, New Delhi.

Dr. M. Gourie Devi: Sri Ganga Ram Hospital, New Delhi.

Dr. Ashoo Grover: Non Communicable Diseases Division, Indian Council of Medical Research, New Delhi.

Dr. Kameshwar Prasad: Department of Neurology, Neurosciences Centre, All India Institute of Medical Sciences, New Delhi.

Dr. A. Nanda Kumar: National Centre for Disease Informatics and Research, Bangalore.

Dr. Thankappan K.R.: Sree Chitra Tirunal Institute for Medical Sciences and Technology, Kerala.

Dr. P. Satish Chandra: National Institute of Mental Health and Neuro Sciences, Bangalore.

Dr. K. Radhakrishnan: Kasturba Hospital, Manipal, Karnataka.

References stroke: saving lives around the world. Lancet Neurol 2007;6:182-187.

2 Feigin VL, Forouzanfar MH, Krishnamurthi R, Mensah GA, Connor M, Bennett DA, Moran AE, Sacco RL, Anderson L, Truelsen T, O’Donnell M, Venketasubramanian N, Barker-Collo S, Lawes CM, Wang W, Shinohara Y, Witt E, Ezzati M, Naghavi M, Murray C; Global Burden of Diseases, Injuries, and Risk Factors Study 2010 (GBD 2010) and the GBD Stroke Experts Group: Global and regional burden of stroke during 1990-2010: findings from the Global Burden of Disease Study 2010. Lancet 2014;383:245-254.

3 Wahab KW: The burden of stroke in Nigeria. Int J Stroke 2008;3:290-292.

4 Cheng XM, Ziegler DK, Lai YH, Li SC, Jiang GX, Du XL, Wang WZ, Wu SP, Bao SG, Bao QJ: Stroke in China, 1986 through 1990. Stroke 1995;26:1990-1994. 
5 Wu Z, Yao C, Zhao D, Wu G, Wang W, Liu J, Zeng Z, Wu Y: Sino-MONICA project: a collaborative study on trends and determinants in cardiovascular diseases in China, Part i: morbidity and mortality monitoring. Circulation 2001;103:462-468.

6 Jiang B, Wang WZ, Chen H, Hong Z, Yang QD, $\mathrm{Wu}$ SP, Du XL, Bao QJ: Incidence and trends of stroke and its subtypes in China: results from three large cities. Stroke 2006;37:63-68.

7 Minelli C, Fen LF, Minelli DP: Stroke incidence, prognosis, 30-day, and 1-year case fatality rates in Matão, Brazil: a population-based prospective study. Stroke 2007;38:2906-2911.

8 Lavados PM, Sacks C, Prina L, Escobar A, Tossi C, Araya F, Feuerhake W, Galvez M, Salinas R, Alvarez G: Incidence, 30-day case-fatality rate, and prognosis of stroke in Iquique, Chile: a 2-year community-based prospective study (PISCIS project). Lancet 2005;365:2206-2215.

9 Tsiskaridze A, Djibuti M, van Melle G, Lomidze G, Apridonidze S, Gauarashvili I, Piechowski-Józwiak B, Shakarishvili R, Bogousslavsky J: Stroke incidence and 30-day case-fatality in a suburb of Tbilisi: results of the first prospective population-based study in Georgia. Stroke 2004;35:2523-2528.

10 Danesi MA, Okubadejo NU, Ojini FI, Ojo OO: Incidence and 30-day case fatality rate of first-ever stroke in urban Nigeria: The prospective community based epidemiology of stroke in Lagos (EPISIL) phase II results. J Neurol Sci 2013;331:43-47.

11 Das SK, Banerjee TK, Biswas A, Roy T, Raut DK, Mukherjee CS, Chaudhuri A, Hazra A, Roy J: Prospective community-based study of stroke in Kolkata, India. Stroke 2007;38:906910.
12 Banerjee TK, Dutta S, Ray BK, Ghosal M, Hazra A, Chaudhuri A, Das SK: Disease burden of stroke in Kolkata, India: derivation of disability-adjusted life years by a direct method. Neuroepidemiology 2013;41:8893.

13 Sridharan SE, Unnikrishnan JP, Sukumaran S, Sylaja PN, Nayak SD, Sarma PS, Radhakrishnan K: Incidence, types, risk factors, and outcome of stroke in a developing country: the Trivandrum stroke registry. Stroke 2009;40:1212-1218.

14 Dalal PM, Malik S, Bhattacharjee M, Trivedi ND, Vairale J, Bhat P, Deshmukh S, Khandelwal K, Mathur VD: Population-based stroke survey in Mumbai, India: incidence and 28day case fatality. Neuroepidemiology 2008; 31:254-261.

15 Feigin VL: Stroke in developing countries: can the epidemic be stopped and outcomes improved? Lancet Neurol 2007;6:94-97.

16 Pandian JD, Kalra G, Jaison A, Deepak SS, Shamsher S, Padala S, Singh Y, Abraham G: Factors delaying admission to a hospitalbased stroke unit in India. J Stroke Cerebrovasc Dis 2006;15:81-87.

17 The Global Summit on Civil Registration and Vital Statistics, April 18-19, 2013.

18 WHO STEPS Stroke Manual Version 1.2. The WHO STEP wise approach to stroke surveillance. http://www.who.int/ncd_surveillance/ en/steps_stroke_manual_v1.2.pdf (accessed July 2, 2010).
19 American Diabetes Association: Diagnosis and classification of diabetes mellitus. Diabetes Care 2008;31:S55-S60.

20 Carretero OA, Oparil S: Essential hypertension. Part I: definition and etiology. Circulation 2000;101:329-335.

21 ATP III Guidelines At-A-Glance Quick Desk Reference. National Cholesterol Education Program. http://www.nhlbi.nih.gov/guide lines/cholesterol/atglance.pdf (accessed July 2, 2010).

22 Gutierrez C, Blanchard DG: Atrial fibrillation: diagnosis and treatment. Am Fam Physician 2011;83:61-68.

23 MRC European Carotid Surgery Trial: interim results for symptomatic patients with severe $(70-99 \%)$ or with mild (0-29\%) carotid stenosis. European Carotid Surgery Trialists' Collaborative Group. Lancet 1991;337:12351243.

24 Braunwald E, Antman EM, Beasley JW, Califf RM, Cheitlin MD, Hochman JS, Jones RH, Kereiakes D, Kupersmith J, Levin TN, Pepine CJ, Schaeffer JW, Smith EE 3rd, Steward DE, Theroux P, Gibbons RJ, Alpert JS, Eagle KA, Faxon DP, Fuster V, Gardner TJ, Gregoratos G, Russell RO, Smith SC Jr: ACC/AHA guidelines for the management of patients with unstable angina and nonST-segment elevation myocardial infarction: executive summary and recommendations. A report of the American College of Cardiology/American Heart Association task force on practice guidelines (committee on the management of patients with unstable angina). Circulation 2000;102:11931209.
Feasibility of Population Based Stroke Registry
Neuroepidemiology 2015;44:69-77 DOI: $10.1159 / 000371520$ 